\title{
DESCOBRIR O VALOR EM \\ APRENDER SOBRE SUSTENTABILIDADE: \\ UM CASO DE ENSINO NO \\ PROGRAMA STRICTO SENSU EM ADMINISTRAÇÃO
}

\author{
DISCOVERING THE VALUE OF LEARNING \\ ABOUT SUSTAINABILITY: \\ A TEACHING CASE FOR \\ POSTGRADUATE COURSES IN ADMINISTRATION
}
Recebido em: 30/05/2012 Aprovado em: 03/07/2012 Avaliado pelo sistema double blind review Editora Científica: Manolita Correia Lima

\section{MARIALVATOMIO DREHER marialvatomio@yahoo.com.br \\ LÚCIASEVEGNANI \\ UNIVERSIDADE REGIONAL DE BLUMENAU}

\section{RESUMO}

No nível de pós-graduação stricto sensu os estudantes precisam ser estimulados a interpretar teorias e a exercitar seus posicionamentos diante de discussões científicas e empíricas. Nesse sentido, desenvolveu-se este caso de ensino, cujo objetivo é apresentar uma experiência de ensino voltada à dimensão ambiental, na disciplina "Governança e Sustentabilidade", oferecida por um programa de pós-graduação stricto sensu em Administração. No decorrer desta experiência, os sujeitos partícipes do estudo foram cinquenta e nove (59) estudantes que, nos três últimos anos, cursaram a disciplina suprarreferida. A prática pedagógica utilizada na disciplina em questão foi denominada de participativa, pois reúne o rigor acadêmico, controlado pelo professor, com as demandas e a criatividade dos estudantes, unidas num processo de construção pedagógica coletiva, à luz dos postulados de Freire. No início das atividades da disciplina, verificou-se que os alunos possuíam um baixo nível de compreensão sobre o ambiente natural e suas singularidades. Todavia, com base nos diálogos, debates e visitas técnicas realizadas no decorrer do semestre, observa-se significativa mudança na compreensão e comportamento dos acadêmicos em relação à temática ambiental e à sustentabilidade.

Palavras-chave: ensino de administração; stricto sensu; sustentabilidade.

\section{ABSTRACT}

At the postgraduate level, students must be encouraged to interpret theories and position themselves as regards empirical, scientific discussions. Accordingly, we developed this teaching case, whose purpose is to provide an educational experience focused on the environmental dimension, in the "Governance and Sustainability" class of a postgraduate course in Business Administration. During this experiment, the subjects of the study comprised fifty-nine (59) students who had enrolled in the subject over the past three years. The pedagogical practice used in the discipline in question was referred to as participatory as it combines the academic requirements, controlled by the teacher, with creativity and the demands of the students, which come together in a joint teaching construction in the light of the postulates of Freire. At the start of the course, it was found that the students had a low level of understanding of the natural environment and its singularities. However, during the dialogues, debates and technical visits proposed over the course of the semester, a significant change in the students' understanding and behavior regarding environmental issues was observed.

Keywords: administration courses; postgraduate; sustainability. 


\section{AS PALAVRAS INICIAIS}

Este é um bom tempo para "aprender" alguns aspectos intrínsecos da biodiversidade. Muitas falas, muito barulho e muitos movimentos vêm sendo experimentados nessa área. Isso, no entanto, deve ser tratado com cuidado.

Em muitos campos do ensino, a sustentabilidade tem sido alvo de acirradas discussões. Um dos fatores que incentivou este debate foi a Conferência Rio-92, cujos resultados apontam o engajamento de todos os países em prol da educação para a sustentabilidade como fator preponderante para desenvolvimento sustentável (BLEWITT; CULLINGFORD, 2004). Desde então, muitos movimentos acadêmicos surgiram para suprir esta demanda. Contudo, tal reação pode ser considerada lenta se comparada ao envolvimento dos egressos em causas ambientais.

As intervenções do ser humano sobre o ecossistema e a deterioração dos recursos naturais continuam a provocar acidentes em todos os cantos do mundo. As catástrofes ocorridas nos últimos anos não foram suficientes para que fosse priorizada a educação ambiental em nosso currículos. Isso não é diferente na área de Administração, na qual, segundo a população pesquisada neste estudo, ainda é um desafio construir um elo entre os interesses das organizações e o termo sustentabilidade.

Conforme Barbieri (2004), na maioria dos programas de cursos superiores, a educação ambiental limita-se à realização de atividades isoladas no dia do meio ambiente ou aos programas de coleta seletiva de lixo, em dependências da instituição. As exigências legais, que vêm aumentando desde meados da década de 1970, pouco repercutem nos cursos de Administração, pois nestes mantém-se a percepção equivocada de que problemas ambientais são inerentes à produção e que, por isso, devem ser resolvidos por especialistas desta área.

Ainda que tais temas surjam no decorrer do processo de ensino e aprendizagem - tanto na graduação em Administração quanto em outros cursos - a ideia consolidada de especializar-se em determinada 
área, como se esta pudesse ser dissociada do contexto, diminui interesse e, por consequência, o envolvimento do estudante com questões políticas e conceituais mais amplas, especialmente quando a compreensão de tais dilemas envolve conhecimentos multi e transdisciplinares, como é o caso da sustentabilidade. Não obstante, a assimilação de tais saberes ampliaria significativamente a visão de mundo do estudante de administração, pois este reuniria subsídios para perceber que tudo está integralmente relacionado ao ambiente, inclusive, à sobrevivência da humanidade, que depende de elementos imprescindíveis como água, ar puro e um clima que lhe permita extrair alimentos e outros recursos da natureza.

Num nível mais elevado da formação em Administração, como o stricto sensu, questões como estas poderiam ser vistas como fundamentais, e não isoladamente, como mais um gueto científico. Não se trata da defesa de uma área em detrimento das outras, mas da necessidade emergencial de um programa de ensino, que integre novos conhecimentos, em torno de temas que transcendam a sala de aula e o cotidiano das organizações. Esta transdisplinaridade, porém, parece ainda não ter sido incorporada pelos programas de pós-graduação em Administração que, por enquanto, se atêm às especificidades das disciplinas previstas em sua matriz curricular.

Neste artigo, relata-se a experiência de ensino e aprendizagem vivenciada na disciplina "Sustentabilidade e Governança", ofertada em um curso de Mestrado e Doutorado em Administração, da Região Sul do País. Ressaltase que, neste estudo, a questão da sustentabilidade é primordial, já que a governança é abordada como um processo de gestão coletivamente ordenado e transparente, que contribui para o desenvolvimento da sustentabilidade na área pública e nas organizações.

Para a coleta de dados, realizamos as observações in loco foram registradas em diários de campo durante todo o processo de ensino. Posteriormente, foram entrevistados cinquenta e nove estudantes, que cursaram a disciplina "Sustentabilidade e Governança" nos últimos três anos. Após a coleta, os dados foram organizados, considerando-se os aspectos mais relevantes para evidenciar o posicionamento acerca do objeto estudado. Para atenuar o empirismo, durante a análise dos dados, os eventos observados foram 
associados à teoria, visando materializar detalhes que poderiam passar despercebidos. Foram Resguardadas as limitações que o recorte teórico e empírico impõe sobre o caso estudado, salientando a necessidade de novas pesquisas, com outras reflexões sobre o processo de ensino e a aprendizagem da sustentabilidade na área de Administração. Afinal, ensinar e aprender são eventos que dependem de cada experiência vivenciada. 


\section{REFERENCIAL TEÓRICO}

Ensinar é uma arte, na qual os conteúdos, os exercícios e sua compreensão representam o palco da vida. A escola é o cenário, é a produção de uma peça.

O ensino no nível superior reflete uma posição privilegiada, pois permite a produção de conhecimentos em torno de temas importantes como: riqueza, pobreza, segurança, ambiente, economia global e de suas diversas consequências. O ensino ajuda a moldar a realidade material experimentada e as formas pelas quais se tenta compreender, refletir e, quando necessário, alterar o próprio processo de ensino (BEWITT; CULLINGFORD , 2004). Esta noção de ensino deveria ser inerente aos diversos campos do conhecimento. No entanto, isso não ocorre com frequência porque muitas universidades estão privatizando sua função pública e neutra de geração de conhecimento. Chauí (20II, p. 2) alerta para o fato de que:

as discussões que têm sido feitas a respeito da universidade giram em torno do modo em que ela deva se relacionar com o mercado. E não há uma alma que seja para dizer: Mas, por que essa relação é fundamental? Ou seja, não só se toma que é assim, mas se toma isso como um destino necessário. [...] Essa postura consiste em fazer com que o jogo do mercado seja considerado a última ratio, ou seja, o fundamento de toda a racionalidade. O mercado, portanto, se tornou não só o fim da história, a fatalidade humana e a naturalização das relações sociais, mas também o cerne onde se decide o que é racional e o que é irracional. A consequência disso é o fechamento da ideia de que as coisas podem ser diferentes, que precisam ser diferentes e que devem ser diferentes. Fica ocultado que o mercado, e o seu funcionamento, é uma instituição produzida pela ação dos homens e que pode ser desfeita por ela. Desaparece, portanto, a ideia de outra realidade possível construída por nós mesmos.

Essa é forma particular pela qual as universidades vêm se moldando, sem reconhecer o dinamismo e multiplicidades intrínsecas em seu papel de agentes de transformação social. Formar profissionais para o mercado? Ou 
formar sujeitos pensantes, ativos no seu contexto social? No caso do ensino de administração, certamente este desafio é ainda mais complexo (CAVEDON, 2008), pois prepondera a herança teórica do utilitarismo, do pragmatismo do fazer administrativo em prol de uma visão mais compreensiva e interpretativa da realidade.

De modo geral, há demandas para que a sociedade se motive e se mobilize para assumir um papel mais propositivo, a fim de que, de forma concreta, questione a si própria e ao governo pela falta de iniciativas para implementação de políticas e ações de sustentabilidade. Nesse sentido, o problema ambiental constitui um tema muito propício para aprofundar a reflexão e a prática em torno do restrito impacto das práticas de resistência e de expressão das demandas da população das áreas mais afetadas pelos constantes e crescentes agravos ambientais (JACOBI, 2003).

Freire (1996, p. 24) ressalta que "a reflexão crítica sobre a prática se torna uma exigência na relação Teoria/Prática, sem a qual a teoria pode ir virando blábláblá e a prática, ativismo.” A consciência ambiental é uma atitude nada passiva em relação às mazelas que existem, é um agir atento e profundo no âmago da questão. Este argumento caberia ao nível stricto sensu da pós-graduação, o qual, no Brasil, segundo Lüdke (2005), propõe-se a atender fatores epistemológicos e de cunho sociopolítico na formação de pesquisadores e professores.

Os cursos de mestrado e doutorado compreendem uma área de concentração (major) à escolha do estudante e matérias de uma área conexa (minor). Para o doutorado, a tese é obrigatória, enquanto para o mestrado pode ser exigida uma dissertação ou outro tipo de trabalho escrito. Este nível de exigência contempla a preocupação com o desenvolvimento da pesquisa, por meio dos cursos de pós-graduação, para atender às necessidades de desenvolvimento do próprio País. Os programas definem as linhas de atuação, de acordo as propostas institucionais de cada universidade, sempre amparadas pela experiência dos professores/ pesquisadores, que conduzem os processos de ensino, de pesquisa e de orientação dos estudantes. 
Raths et al. (1976) afirmam que é necessário ter coragem e resistência para enfrentar os resultados da pesquisa e da reflexão, pois a dúvida é criada da pesquisa. Os estudantes dos Programas stricto sensu, entre eles os da área da administração, precisam extrapolar os limites do seu feudo de especialização, arguir e defender seus questionamentos como parte do crescimento científico, pois este nível é propício para reflexões mais holísticas, como é o caso da sustentabilidade.

Desde 1990, cerca de I.000 instituições acadêmicas de todo o mundo assinaram declarações internacionais comprometendo-se com a implementação de projetos educacionais, que contemplem a sustentabilidade, em especial, no que concerne à estrutura curricular; ao desenvolvimento da pesquisa e a parcerias com o governo, organizações não governamentais e indústrias para articulação de ações na referida área. Isso, contudo, é apenas o começo. Há muito a ser feito para que a educação para o desenvolvimento sustentável possa ser verdadeiramente vivenciado nas universidades (WAAs; VERBRUGGEN; WRIGHT, 20IO).

Na essência, o termo sustentabilidade refere-se ao equilíbrio entre a proteção ambiental e o desenvolvimento, visto como um processo de transformação, que ordena e organiza o crescimento econômico com as demandas sociais e culturais, reconhecendo os limites físicos impostos pelos ecossistemas. Para a World Commission on Environment and Development (1987), a sustentabilidade se traduz na qualidade do desenvolvimento sustentável, em um novo "modelo" que preconiza a satisfação das necessidades presentes, sem comprometer a capacidade das gerações futuras de suprir as próprias necessidades. Neste estudo, concebe-se a sustentabilidade nas suas diferentes dimensões: econômica, ambiental e social, todas absolutamente inter-relacionadas.

Conforme Blewitt e Cullingford (2004), embora estes princípios sejam importantes no cotidiano do ensino de administração, questões como gestão, finanças, desenvolvimento de carreira, ensino e aprendizagem demandam maior esforço por parte dos acadêmicos. O desafio do professor está em articular a educação para a sustentabilidade com estas temáticas. 
Os lideres acadêmicos - de todos os níveis - precisam buscar métodos de ensino, currículos e políticas de gestão educacional que sensibilizem os estudantes para a causa ambiental, mobilizando-os em prol de um mundo mais sustentável.

Um projeto de sustentabilidade não pode limitar-se à dimensão econômica; é preciso também levar em conta o equilíbrio entre as dimensões sociais, ambientais e culturais, haja vista que estamos lidando com a co-evolução de dois sistemas regidos por escalas espaciais e temporais distintas. O tempo de sustentabilidade das civilizações dependerá da capacidade destas de as mesmas assimilarem preceitos ecológicos e fazerem bom uso dos recursos naturais. Segundo Sachs (2004, p.I), a expressão desenvolvimento sustentável deveria ser desdobrada em "socialmente includente, ambientalmente sustentávele economicamente sustentado no tempo".

Segundo Jacobi (2003), a sustentabilidade busca uma forma de desenvolvimento que supere o reducionismo, estimula um pensar e um fazer - sobre o meio ambiente - diretamente vinculado ao diálogo entre saberes, à participação, aos valores éticos como essenciais para fortalecer a complexa interação entre sociedade e natureza. Numa educação compromissada com a formação de valores voltados à sustentabilidade, o papel do professor é essencial para impulsionar as transformações.

A problemática socioambiental, ao questionar ideologias teóricas e práticas, propõe a participação democrática da sociedade na gestão dos seus recursos atuais e potenciais, assim como no processo de tomada de decisões para a escolha de novos estilos de vida e a construção de futuros possíveis, sob a ótica da sustentabilidade ecológica e a equidade social. Torna-se cada vez mais necessário consolidar novos paradigmas educativos, centrados na preocupação de iluminar a realidade desde outros ângulos, e isto supõe a formulação de novos objetos de referência conceituais e, principalmente, a transformação de atitudes (JACOBI, 2003, p. 200).

Fornet-Betancourt (2007) afirma, no entanto, que o desenvolvimento sustentável, ou como preferem dizer outros, de desenvolvimento com futuro e para o futuro, mais do que uma solução, parece ser o indicador de problema, pois as reivindicações da sustentabilidade deixam claro que 
o regime econômico imposto à humanidade, assim como o modelo de civilização que o mantém, representa um processo histórico insustentável. Em suma: a sustentabilidade problematiza a insustentabilidade do que hoje somos e fazemos. Talvez, a sustentabilidade seja uma "solução" tímida, que se inscreve no horizonte paradigmático do problema que apresenta e que, por isso, precisa ser radicalmente repensada? Esta proposta "bem intencionada" não negligencia um modelo insustentável? Questões como esta servem de base para reflexões mais profundas, abstraídas da experiência de ensino apresentada neste estudo, as quais repensam, por exemplo, o sentido da própria ecologia. 


\section{AS PRÁTICAS DE UM CASO DE ENSINO APRENDIZAGEM}

A estrutura da disciplina aqui relatada é dividida em nove diferentes módulos, com uma carga horária total de quarenta e cinco créditos/aula. Estes módulos foram organizados em um esforço conjunto, no decorrer das aulas, entre professores e alunos. A intenção foi contribuir com a construção coletiva da escolha dos conteúdos teóricos e empíricos. Dessa maneira, os módulos foram estruturados, com base nas questões, críticas e vivências apresentadas no decorrer dos debates do grupo.

Os objetivos da disciplina são: (a) apresentar e discutir a relação das organizações com a sociedade e o ambiente, incorporando a governança como estratégia administrativa para a sustentabilidade; (b) promover lideranças e docências comprometidas com as demandas sociais e ambientais; (c) ampliar o escopo de pesquisas na área social e ambiental no contexto da administração. A intenção foi construir o aprendizado pela pedagogia participativa.

Os módulos foram construídos baseados nas reflexões: (I) ambiente, sociedade e organizações; (2) ecologia e biodiversidade: (3) desenvolvimento sustentável; (4) sustentabilidade; (5) indicadores de sustentabilidade; (6) gestão ambiental; (7) atividade prática no campo; (8) governança; e (9) processo de governança e sustentabilidade.

A avaliação e seus devidos pesos/notas consistem nos seguintes critérios e objetivos:

a) Participação e assiduidade (peso $\mathrm{I}, \mathrm{o}$ ): motiva a participação ativa nas aulas e valoriza os esforços na construção coletiva das reflexões. Nesta experiência de ensino, a organização das discussões foi realizada por meio da ordenação e cumprimento dos objetivos teóricos de cada módulo.

b) Notas de leitura (peso 2,o): estimula a leitura e o compartilhamento de conhecimentos consolidados por autores da área. No primeiro dia de aula, o professor apresentou os teóricos da área e orientou os alunos para uma pesquisa sobre os principais estudos, que abarcam a temática. Depois da busca, o grupo selecionou os textos a serem trabalhados. O conteúdo do texto selecionado para leitura e a discussão de cada módulo representou 
o principal foco de reflexão em sala de aula. Em geral, esta discussão foi provocada e assumida por uma dupla de estudantes. Ressalta-se, no entanto, que todos os estudantes foram provocados a participar; não caracterizando, de modo algum, uma aula somente expositiva.

c) Pesquisa sobre casos práticos de sustentabilidade e governança (peso, 2,0): provoca os estudantes a gerarem entendimentos sobre as atuais ações praticadas na área e suas devidas limitações. Foi realizada uma pesquisa de campo em organizações locais ou regionais.

d) Prova Escrita (peso 2,0): dá oportunidade à elaboração de reflexões escritas sobre a temática. A prova foi composta por questões acerca das contextualizações discutidas em aula e apresentou, como base de análise teórica, as leituras discutidas nos módulos. Valorizou-se, neste sentido, o esforço das notas de leitura.

e) Elaboração de artigo científico sobre os resultados da pesquisa, o qual pode ser sintonizado com o objeto dos trabalhos de conclusão de curso (tese ou dissertação) (peso, 3,0): estimula um posicionamento final do estudante sobre o tema desenvolvido. Na experiência em questão, procurou-se articular a sustentabilidade com as demandas dos trabalhos finais de cada estudante. O objetivo era demonstrar que a sustentabilidade precisa ser vista como interdisciplinar e que, de algum modo, sempre permeia outras discussões.

A metodologia participativa foi inspirada nas propostas da Pedagogia da Autonomia de Freire (1996, p.I2), que se inspira no exercício de "saber-fazer, na autorreflexão crítica e no saber-ser da sabedoria". Esta metodologia foi aplicada desde o início dos trabalhos. A intenção foi desenvolver o pensamento e a socialização das ideias em um espaço propício a novos diálogos e reflexões. Além disso, buscou-se a construção de um espaço de diálogos mais democráticos (CHAUí, 200I), afinal cabe ao nível stricto sensu preparar os futuros mestres para enfrentar os desafios da educação.

$\mathrm{Na}$ etapa de organização da disciplina, alguns estudantes resistiram às aberturas dadas para discussão, especialmente aqueles que sempre receberam o "pacote pronto" em planos de trabalho predefinidos. É possível que o condicionamento da tradição autoritária também tenha interferido 
neste processo. Para Raths (1976, p. 159), "poucos negarão que precisamos deixar de lado os pronunciamentos ex-cátedra, a obediência aos deuses, que são apresentados como parte da devoção. Às vezes, e apesar das declarações contrárias, os professores realmente não desejam que o pensamento seja uma consequência do ensino".

Não se pode desconsiderar que há também os efeitos de certa alienação quanto ao esforço intelectual necessário a uma nova atividade, especialmente no nível stricto sensu, em que estudantes são professores universitários. Por vezes, a lamúria dos "sem tempo" persiste. Construir juntos significa comprometer-se e estar acessíveis a críticas. Conforme Raths (1976), para alimentar os processos de pensamento, é preciso criar consciência de atitudes e táticas que favoreçam o entendimento, e isso se dá na aproximação entre professor e aluno.

É terrivelmente fácil criticar o outro e suas ideias. Talvez seja ainda mais fácil fazer criticas ou ser neutro quando estamos diante de questões objetivas. Se pensamento significa alguma coisa, significa crítica do eu. Os professores devem estar preparados para aceitar as críticas dos alunos, pois na realidade a crítica é a vida da vida e é certamente a vida da ciência e da arte (RATHS, 1976, p. I6I).

A metodologia empregada para promover uma discussão mais profunda sobre ecologia foi construída com base na multidisciplinaridade. O planejamento das aulas - conteúdo e didática - foi elaborado, em conjunto, pelos docentes das Áreas de Administração e Ciências Naturais que, desde o início, participaram da concepção da disciplina. Seguindo este planejamento, no decorrer das aulas, promoveu-se um seminário sobre ecologia, mediado por um docente formado em Botânica e Biologia, com experiência acadêmica e profissional na área das Ciências Naturais. Também foi feita uma visita técnica a áreas preservadas e não preservadas, criando oportunidade para que o estudante estabelecesse contato direto com problemas ambientais e, ao mesmo tempo, se sensibilizasse com a prazerosa observação das fragilidades e da beleza de ecossistemas conservados. 
E essa rigorosidade metódica não tem nada que ver com o discurso "bancário" meramente transferidor do perfil do objeto ou do conteúdo. É exatamente neste sentido que ensinar não se esgota no "tratamento" do objeto ou do conteúdo, superficialmente feito, mas se alonga à produção das condições em que aprender criticamente é possível. E essas condições implicam ou exigem a presença de educadores e de educandos criadores, instigadores, inquietos, rigorosamente curiosos, humildes e persistentes. Faz parte das condições em que aprender criticamente é possível a pressuposição por parte dos educandos de que o educador já teve ou continua tendo experiência na produção de certos saberes e que estes não podem a eles, os educandos, ser simplesmente transferidos (FREIRE, I996, p.29).

Ressalta-se que esta metodologia, embora pouco empregada no curso stricto sensu, vem se destacando e obtendo boa avaliação por parte dos discentes que dela participam, não sendo, de forma alguma, percebida por eles como um método inadequado a este nível de ensino. Essa aceitação, por parte dos estudantes, com certeza, motiva os docentes envolvidos a seguirem neste caminho pedagógico.

Para relatar alguns dos resultados do ensino promovido na disciplina "Sustentabilidade e Governança”, especificamente no que tange à busca pela maior sensibilização para apreender sobre o viés ambiental e ecológico da sustentabilidade, apresenta-se, inicialmente, o perfil dos estudantes que a cursaram. Até o presente momento concluíram a disciplina cinquenta e nove (59) estudantes: vinte e sete (27) mulheres e trinta e dois (32) homens, com idade média de trinta e quatro (34) anos (menor 23 e o maior 52 anos). A maioria (48) possui formação na área de Ciências Sociais Aplicadas com concentração (38 deles) em Administração. Seis (6) possuem formação na área da Saúde, três (3) em Ciências Exatas e três (3) em Ciências Naturais em Agronomia. Ao ingressar no mestrado, muitos deles pretendiam exercer a profissão da docência; destes, vinte e dois (22) já estão atuando em universidades.

Um fator que chama a atenção e pode ser considerado como um diferencial são as mudanças que esta disciplina despertou nos estudantes. Durante este curto período de formação, três anos, trinta e um (3I) 
estudantes se comprometeram com causas ambientais, a saber: três (3) conseguiram desenvolver e implantar o balanço social nas universidades em que trabalham; quatro (4) estão atualmente envolvidos em processos de gestão ambiental nas organizações em que trabalham; dois (2) tornaramse flexitarianos (raramente comem carne); doze (I2) optaram por elaborar dissertações que discutem os problemas da sustentabilidade; oito (8) desenvolvem a problemática ambiental em sala de aula; dois (2) pretendem cursar doutorado na área das ciências naturais.

A necessidade de abordar o tema da complexidade ambiental decorre da percepção sobre o incipiente processo de reflexão acerca das práticas existentes e das múltiplas possibilidades de, ao pensar a realidade de modo complexo, defini-la como uma nova racionalidade e um espaço onde se articulam natureza, técnica e cultura. Refletir sobre a complexidade ambiental abre uma estimulante oportunidade para compreender a gestação de novos atores sociais que se mobilizam para a apropriação da natureza, para um processo educativo articulado e compromissado com a sustentabilidade e a participação, apoiado numa lógica que privilegia o diálogo e a interdependência de diferentes áreas de saber. Mas também questiona valores e premissas que norteiam as práticas sociais prevalecentes, implicando mudança na forma de pensar e transformação no conhecimento e nas práticas educativas. (JACOBI, 2003, p.rigr).

Este envolvimento é acompanhado por meio do diálogo, que ainda existe entre os professores e os estudantes mais envolvidos (citados acima). Podese afirmar que, atualmente, há uma rede de apoio mútuo no sentido de contribuir com as iniciativas que já estão sendo desenvolvidas e promover as que estão em fase de idealização. Este é um movimento raro no curso stricto sensu em Administração, uma vez que há, evidentemente, maior preocupação com os conteúdos voltados à gestão das organizações.

A dinâmica de ensino aqui apresentada inclui-se numa perspectiva educativa que concebe a produção do conhecimento como um processo de re(significação); que sensibilize para questões socioambientais, estimule a criatividade, a cooperação, a participação, enfim, o engajamento dos estudantes na construção de um mundo melhor. Isso tudo na Administração? 
Na pós-graduação? Realmente, até o momento, tais espaços são pouco reconhecidos pela sua capacidade de formação e de inserção social.

Memorizar a gestação do problema é viajar para as suas raízes para tornar presente a origem das consequências que padecemos. É, pois, o "método" para compreender que esforços alternativos como os da sustentabilidade têm que buscar sua força na capacidade de contradizer a origem do que fazemos e somos, e não só em estratégias corretoras do curso do desenvolvimento atual, que chegamos a sua fonte. (FORNET-BETANCOURT, 2007, p. 4IO).

Como no curso stricto sensu uma das preocupações é a promoção de discussões mais amplas e profundas acerca das ciências é importante ressaltar que este esforço poderia atrelar-se à seguinte preocupação: "As ciências devem estar a serviço da humanidade como um todo, e devem contribuir para proporcionar a todos uma compreensão mais profunda da natureza e da sociedade, uma melhor qualidade de vida e um meio ambiente sustentável e saudável para o presente e o futuro gerações." (WAAs; VERBRUGGEN; WRIGHT, 20IO, p. 629). 


\section{CONSIDERAÇÕES FINAIS}

Neste artigo, apresentam-se os resultados de um exercício de docência produzido, nos últimos três anos, na disciplina "Governança e Sustentabilidade", em cursos de mestrado e doutorado de um programa de pós-graduação stricto sensu em Administração do Sul do País. No princípio, observa-se que os conhecimentos dos ingressantes sobre sustentabilidade, ecologia e problemas ambientais eram bastante superficiais. Não era esperado um conhecimento aprofundado por não ser este o foco de interesse da formação em Administração porém, um nível tão baixo de conhecimento parece algo alarmante, que precisa ser urgentemente repensado. Ao que parece, embora os debates sobre causas ambientais e os movimentos em prol da sustentabilidade permeiem a sociedade e as organizações, os cursos de graduação em Administração ainda não empreendem esforços suficientes para que seus egressos possam atender às demandas que surgem do cenário socioambiental.

Vale destacar, entretanto, que a aceitação desta dificuldade fez com que a metodologia de trabalho, construída na disciplina apresentada, fosse discutida de modo participativo com os estudantes. A intenção foi desencadear, em conjunto com esses estudantes, um processo que ampliasse as possibilidades de uma aprendizagem significativa sobre a sustentabilidade ambiental.

Observou-se, no decorrer do processo educativo, que a curiosidade despertada levou estudantes a buscarem conhecimentos teóricos mais profundos sobre ecologia. Tais conhecimentos associados à prática - por meio de visitas técnicas que permitiram a observação dos problemas reais enfrentados na região na qual o Programa se situa e onde vivem muitos de seus estudantes - com certeza, contribuíram muito para a sensibilização destes estudantes para a importância da sustentabilidade. Em outras palavras, a união da teoria (na forma como foi conduzida) com a observação in loco provocou uma mudança de comportamento neles. Devido a isso e aos excelentes resultados das ações praticadas por egressos do curso em questão, 
pode-se dizer, humildemente e com muita satisfação, que foi possível a aproximação do que Freire denomina de "prática educativa vivida".

A prática pedagógica utilizada na disciplina em questão foi denominada como participativa, pois reúne o rigor acadêmico, controlado pelo professor, com as demandas e a criatividade dos estudantes, unidas num processo de construção pedagógica coletiva. É evidente que estasinovações, na tradicional forma do programa strictu senso em Administração, especificamente do caso estudado, também sofreram forte influência dos olhares dos professores da área de Ciências Naturais que participam do processo, especialmente pela maneira como estes compartilharam sua leitura dos problemas do mundo.

Conclui-se que urge a necessidade de se reconhecer o ensino stricto sensu como algo (trans)formador; que pode e deve dar valor a questões que possam contribuir para uma vida mais digna dentro e fora da academia, como é o caso preservação ambiental. Por fim, ressalta-se que, de modo algum, pretende-se apresentar esta experiência como inédita ou como a grande solução para a formação de uma consciência ambiental. Sabe-se que muito ainda há para ser apreendido e discutido, a fim de que o processo possa ser continuamente melhorado. O que foi apresentado corresponde aos bons resultados de uma construção conjunta, que só foi conquistada porque houve a participação de estudantes que estavam com bastante disposição para aprender. 


\section{REFERENNCIAS}

BARBIERI, J. C. Educação ambiental e a gestão ambiental em cursos de graduação em administração: objetivos, desafios e propostas. Revista de Administração Pública, v. 38, n. 6, p. 919-946, 2004.

BLEWITT, J.; CULLINGFORD, C. (Eds.). Sustainability curriculum: the challenge for higher educacion. London: Earthscan, 2004.

CAVEDON, N. R. Antropologia para administradores. UFRGS, 2003.

CHAUÍ, M. As humanidades contra o humanismo. In: SANTOS, G. A. (Org.).

Universidade, formação, cidadania. São Paulo: Cortez, 2001, p. 15-32.

FREIRE, P. Pedagogia da autonomia: saberes necessários à pratica educativa. 22.ed. Paz e Terra, 1996.

FORNET BETANCOURT, R. Es la sostenibilidad una perspectiva interculturalmente sostenible? Elementos para la crítica de un concepto bien intencionado, pero insuficiente. Universidad de Bremen. Revista Realidad, n.113, p.409-422, 2007.

JACOBI, P. Educação ambiental, cidadania e sustentabilidade. Cadernos de Pesquisa, n. 118, p. 189-205, 2003.

LÜDKE, M. Influências cruzadas na constituição e na expansão do sistema de pósgraduação stricto sensu em educação no Brasil. Revista Brasileira de Educação, n. 30, p. 117-123, 2005.

RATHS, L.E.; JONAS, A.; ROTHSTEIN, A.M.; WASSERMANN, S. Teaching for thinking: theory and application. Ohio: Company Columbus, 1976.

SACHS, I. Desenvolvimento sustentável: desafio do século XXI. Ambient. soc., v.7, n.2, p.214-216, 2004.

WAAS, T.; VERBRUGGEN, A.; WRIGHT, T. University research for sustainable development: definition and characteristics explored. Elsevier. Journal of Cleaner Production, v. 18, p.629-636, 2010.

WORLD COMMISSION ON ENVIRONMENT AND DEVELOPMENT. Our Common Future. 1987. Disponível em: <http://www.un-documents.net/wced-ocf.htm>. Acesso em: 02/02/2012. 


\section{DADOS DOS AUTORES}

\section{MARIALVA TOMIO DREHER ${ }^{\star}$ marialvatomio@yahoo.com.br} Pós-Doutora em Administração pela UFRGS

Instituição de vinculação: Universidade Regional de Blumenau

Blumenau/SC - Brasil

Áreas de interesse em pesquisa: Sustentabilidade, Responsabilidade Social e Administração.

${ }^{\star}$ Rua Felix Gieseler Senior n518 Velha Blumenau/SC 89041-180

\section{LÚCIA SEVEGNANI luciasevegnani@gmail.com}

Doutora em Ecologia pela USP

Instituição de vinculação atual: Universidade Regional de Blumenau Blumenau/SC - Brasil

Áreas de interesse em pesquisa: Ecologia, Botânica e Educação Ambiental. 